\title{
ALTERNATIIVSEID ETÜMOLOOGIAID I
}

\author{
LEMBIT VABA
}

\begin{abstract}
Annotatsioon. Artiklis esitatakse alternatiivne etümoloogiline tõlgendus eesti sõnadele koost '(puu)lusikas' ja kaugas 'kahekordse pihaga meestesärgi põu, mida kasutati taskuna; rahakott', samuti läänemeresoome keelte põhjarühma sõnale sm kaukalo 'küna, mold' jt.
\end{abstract}

Võtmesõnad: etümoloogia, sõnalaenud, eesti keel, läänemeresoome keeled, balti keeled

\section{Koost'(puu)lusikas'}

Koost : koosta $\sim$ kosta '(puu)lusikas' on murdesõna, mille leviku tuumala on Lääne-Eesti saared ja mida kinnitab ka regilaulukeel. Lääne-Eestist on koost murrete sõnaraamatu andmeil registreeritud Martnast, Karuselt, Hanilast ja Varblast (EMS III,14: 633), samuti on teateid Jõelähtmelt: 'kuostas 'lusikas' (EMS IV,16: 44). EKMSis (II: 704 „Lusikas“) on koosta lääne-eestiline levik ulatuslikum, hõlmates nt Audru. Ernst Särgava romaanis „Lähme linna kirjutama, oma elu kergendama“ markeerib koost omaaegset Vändra keelepruuki, nt „Istuti ja alustati söömist vaikselt, sõna lausumata: pisteti puukoost pudrusse .." (I: 32). Salomo Heinrich Vestringi sõnaraamat „Lexicon Esthonico Germanicum“, kus esineb ohtralt Lääne-Eesti murretele iseloomulikku sõnavara, koost-sõna siiski ei noteeri. Ferdinand Johann Wiedemanni järgi on sõnal koost ka tähendus 'Schuhleisten der Bauern / saapaliist (külakingseppadel)' (Wiedemann 1973; EKMS I: 1245 „Kingsepatöö“), EMS seda ei kinnita.

Julius Mägiste on sõnale esitanud vene etümoloogia, oletades laenamist vanavene laenualusest *kopusta 'segamiskepp või -labidas' (vrd vn murd копьícmь, копьі́стка, копи́стка 'haralise või labidja otsaga segamisriist'). Laenu muganemisel on Mägiste järgi toimunud häälikuareng *kopusta $>$ *koßusta $>$ *kovosta $>$ koost (EEW III: 945). Mägiste etümo- 
loogia on tingimusteta heaks kiitnud SSA (1: 309 sub kapusta). Alo Raun on Mägiste etümoloogia esitanud, kuid lisanud küsimärgi (Raun 1982: 48). Ka Rogier Blokland on aktsepteerinud Mägiste kõrvutuse selle erinevusega, et on rekonstrueerinud lähtekujuks vvn *kobusta (Blokland 2009: 133) - ilmselt selleks, et paremini mõista labiaalklusiili kadu laenus -, mis on aga äärmiselt ebatõenäoline; slaavi sõnatüve ja sellest lähtunud tuletiste etümoloogiat vt täpsemalt ÈSSJa 11: 34-35 sub *kopystb / *kopystъka. Läbipaistvad vene hilislaenud mõnest eespool toodud vene murdesõnast on sm kapusta 'puulusikas', krj kapusta 'puulusikas; (Uhtua) saapaliistu eraldi lisatükk'. Jooseppi Julius Mikkola on arvanud, et e koost : koosta $(<$ kousta $)$ on omasõna, ja juhtinud tähelepanu sellele, et vanimaid lusikaid kasutati rasva koorimiseks toidult ja et need olid kujult selleks sobivad (Mikkola 1938: 66-67).

Mägiste spetsiaalselt käesoleva juhtumi kohta esitatud häälikuareng on ebausutav ja sunnib tema etümoloogiat revideerima. Ka sõna kompaktne lääne-eestiline levikupilt on vene päritolu sõna puhul ebatavaline, kuid see ei ole siiski määrav.

Koost on suure tõenäosusega balti päritolu, lähtudes laenualusest, mille jätkajad on ld kaũste / kaustẽ '1. peitliga õõnestatud vitsteta puunõu, millele on põhi alla pandud / toks medinis indas, kalte iškaltas, be lanko, su ịstatytu dugnu: kausté yra kaip kipelis be rankelés [= koost on käepidemeta veeammutamisnõu, tõstenõu, puust kopsik]; kaũstės buvo apvalios, iškaltos kaltinai su kaltu [koostad olid ümmargused, peitliga õõnestatud]; supilk pupas $i$ didžiają kaũstę, o kanapius $i$ mažaja [puista oad suurde koostasse, aga kanepiseemned väikesse]; kaustẽle [dem] sviesto pridejo ant kelio [koostaga pandi võid teele kaasa]; 2. hobuserautamisriistade kast / arklių kaustymo ịrankių; 3. kõrvadega jooginõu / ąsotas puodelis; 4. sügava alustassi kujuga vanaaegne jooginõu, joogisarv / senovinis gilaus dubenèlio pavidalo geriamasis indas, taurè' ja kaustìne 'nõu toidusse lisatava rasva peeneks tampimiseks; mänd ploomirasva peeneks tampimiseks / indas užtrinui grūsti; užtrinkulis', kaũkštè 'puutüvest õõnestatud väike puunõu / toks medinis išskaptuotas indelis, kaũste, kaltinè, kalkšte’' (http:// www.lkz.lt), vrd siiski ka lt kaũšķ̧ns [k = t'] 'taldrik, kauss või muu nõu, millega (kuivainet) ammutatakse / ein Teller, eine Schüssel od. ein anderes Gefäss, womit (Trockenes) geschöpft wird' (Īvande Kuramaal) (EH I: 596), kaũšksins (Vecauce Zemgales) 'kulp / der Kochlöffel', kaũšksis 'vaagen, liud / die Schüssel' (ME II: 179. 
Kaũste் $\sim$ kaustẽ on deverbaal: $\leftarrow$ káust-yti $\leftarrow$ káu-styti frekv '(hobust) rautama / beschlagen (Pferde)' $\leftarrow$ káuti (káuna / káuja, kóvé kãvo) 'lööma, raiuma, tapma / schlagen, töten' (Smoczyński 2000: 168; vt ka Būga 1959: 458). Leedu vasted levivad Lääne-Leedus Žemaitijas (Rietavas, Plungè, Endriejavas).

Oletan, et balti diftong au on laenamisel korvatud ou-ga, millest seejärel on arenenud pikk $\bar{o}$. Selline substitutsioon ja häälikuareng on iseloomulik liivi keelele, kus diftongid on kvantitatiivses ja enamasti ka kvalitatiivses paradigmaatilises vahelduses, sh ou : o (Posti 1942: 35-36), nt lvK kōsta : sgp koùstõ 'kaust (ree kodaraid piki rege ühendav puu) / Querholz am Schlitten', lōda : sgp loùdõ 'laud, saelaud / Tisch; Brett; Lade', loùtš $\sim$ lōtš (< *lautsi, vrd e lauts : lautsi) '(kapi-, seina-) riiul / Fach im Schrank, Brett an der Wand, um Sachen darauf zu stellen, Regal' (Kettunen 1938: 203ab; $s>$ š tingimusi ja juhte vt Posti 1942: 237-238). Kuid seda lusikanimetust ei ole teadaolevalt liivi keeles registreeritud. Arvan, et koosta ja Lääne-Eesti saarte söögilauanimetuse rend laenuallikas ja oletatav levikutee on sarnased. Nii olen oletanud, et rend on võidud Lääne-Eesti saartele laenata kura (kurši) keele kaudu (Vaba 2009: 779-784). Ka pole sõna rend kohta teateid muudest läänemeresoome keeltest ega murretest. Kurapärast sõnavara leidub leedu keele žemaidi ja läti keele Kuramaa murretes ning liivi keeles. Rend erineb koost-juhtumist siiski selle poolest, et esimeses kajastub kura keelele iseloomulik vanapärane balti tautosüllaabiline ühend $V n$ kui diagnostilise väärtusega häälikutunnus (Vaba 2012: 185-190).

Balti laenu korral on koost läbi teinud semantilise arengu 'puutüvest õõnestatud nõu (ummik)' $\rightarrow$ 'ammutusriist' $\rightarrow$ '(supi)lusikas'. Samalaadne semantiline areng iseloomustab ka läänemeresoome keelte balti laenu *kauha (< blt *kauša 'puutüvest õõnestatud (supi)kulp, kapp, joogianum vms'): L kahv : kahva 'puulusikas', I kavi 'suur kulbisarnane puust õonestatud nõu leili viskamiseks', vdj kavi kaavi 'kulbi moodi kopsik', sm kauha 'kulp, kopsik', is kaavi id., krj kauha kawha, aun kauhu id., lü kauh(e) id., vps kauh $\sim$ kouh $\sim$ kouvaz 'kopp vilja tõstmiseks'. 


\section{Kaugas 'tasku, kahekordse pihaga meestesärgi põu, mida kasutati taskuna; rahakott, rahatasku' ja muu kauka-pere}

Põhiliselt mulgimurdelist sõna kaugas : 'kauka on hiljaaegu püüdnud läti laenuallikaga kabata 'tasku' siduda Udo Uibo (2010: 758-759). Ta on tööhüpoteesina oletanud, et läti laenualusest kabata on kadunud klusiil $b$, sõna lõpposa on asendatud ja see on muganenud ukas- ugas-tuletise sarnaseks. Ta kirjutab: „Eraldades sõnast kaugas oletatava sufiksi -ugas, jääb oletatavat tüve esindama häälikuühend $k a$-, kadunud klusiilainese taastamisel kab-, kad- või kag-. Nüüd pole „tüve“ kab- ja läti sõna kabata 'tasku' esiosa samasust enam raske märgata. Nii et kui eeldada mugandamist, mille puhul läti sõna lõpposa -ata on eesti keeles asendatud sufiksiga -ugas, siis pole võimatu, et siingi on tegu samasuguse läti laenuga nagu märksa lihtsama juhtumi ee lupakas < lt lupata korral." Hilislaenuna on Uibo pakutud läti laenualus pidanud läbima erakordselt keerulise arengutee ega ole veenev. Uibo lisab ka ise, et eesti ja läti sõna ühendab üksnes esisilbi ka-, kõik muu tuleb juurde fantaseerida. Uibo juhib tähelepanu sellelegi, et laenulised on ka taskunimetused kalits, karman ja tasku. Õieti on kõik teadaolevad eesti taskunimetused laenulised, sealjuures suhteliselt hilised laenud. Alamsaksa ja rootsi keelest on laenatud peale juba nimetatud tasku ka task, taski, taska, tasi, ilmselt rootsi keelest vikk 'püksitasku', vene keelest kalits (ka kallits) '(püksi)tasku', karman (ka karmand), läti keelest kalits (ka kallits), kess 'naistetasku', kulit (ka kulita, kullit, kullitu, kulits, kuulit, kullita) '(ripp)tasku'. (Eesti taskunimetuste etümoloogiaid vt ka Saareste 1924: 176-177.)

Eesti rahvaluuleuurijad on taskunimetuste hulka arvanud veel sõna avaski : avaski avasti 'tasku; väike rahakott, pung' (vt ERL IV: 355), mis esineb Mulgi regilaulukeeles (http://www.folklore.ee/regilaul/andmebaas). Sõna leidub ka mitmes vanemas leksikograafilises allikas tähenduses 'vene paun': Awwask 'Ein russischer Beutel' (Vestring 1998: 354); awwask'ein rußischer Beutel' d. (Hupel 1780: 145), awas'k G. awas 'ki (d) 'russischer Beutel' (Wiedemann 1973). Avaski ongi ilmselt vene päritolu, kuid jäänud eesti keele vene laenude uurijate tähelepanuta. Avaski laenualus aвócька 'kandevõrk' on vene etümoloogiasõnaraamatute kinnitusel tuletatud partiklist aвócb 'võib-olla, äkki, ehk' väidetavalt alles Vene kodusõja (1917-1923) aastail kroonilise toidunappuse tingimustes (vt nt Černyh I: 25), s.o hommikul tööle minnes pistis vene resp. nõukogude inimene аво́ська igaks juhuks tasku, et ehk veab ja äkki õnnestub kusagilt söögi- 
poolist hankida, mida авóська'ga koju kanda. Eesti regilaulukeel osutab, et аво́ська peab vene keeles olema märksa vanem.

Kui jätta kõrvale ebarahuldava etümoloogiaga kaugas, on praeguse uurimisseisuga etümoloogiata vaid nääps : nääpsu Jäm Khk Mus Kaa Krj Jaa 'vanaaegne naistetasku'. Andrus Saareste on usutavasti liikunud õiges suunas, kui ta taskunimetuse nääps puhul on juhtinud tähelepanu seelikuvolti tähistavale sõnale niips : niipsu, mille levila VMSi andmeil on Mar Mär Nis Kei Hag (VMS II: 87; vt ka EMS IV: 574-575 „Volt “).

Kaugas ei kuulu hõlpsalt etümologiseeritavate sõnade hulka. Alljärgnev kiirpilk tasku arengulukku loodetavasti selgendab taskunimetuste arengu lähtekohti. Tänapäeval mõeldakse tasku all eelkõige riietusesemele sissepoole või peale õmmeldud lamedaid „mahuteid“, nn kotikesi pisemate ja kergemate tarbeesemete, raha vm kaasaskandmiseks. Rõivatasku eelkäijaid on kaelas, õlal või vööl rippuv lahttasku, milles kanti kaasas tuletegemisvahendeid, raha vms. Peaaegu kuni XIX sajandi lõpuni kandsid naised Eestis laht- ehk vöötaskuid, mis seoti paeltega vööle (Konsin 1977; Troska jt 1995: 122). Lahttaskuid pidasid ka mehed: Hls Vanast olliv mes'tel nahast 'taski kõtu_bäl, rihmage puuste_bäl `kinni pant. Sääl olli piip, tuleraud, tagel ja mund 'raami sehen (VKM VII: 135; lisa lahttaskute ja nende kandmisviisi kohta vt EKMS III: 1224 „Tasku“). Tasku ajaloo käsitlustes rõhutatakse, et rõivaste sisse õmmeldavate taskute tekkele viis peamiselt taskuvaraste kartus. Tänapäeva rõivatasku prototüüp on kott ja Euroopas kõneldud keeltest on võimalik tuua ohtralt näiteid isosemantiliste koti- ja taskunimetuste kohta, mis peegeldavad ilmekalt rõivatasku uuema aja arengujärke, nt sks Tasche '(reisi)paun; rahakott, kukkur; tasku jt'. Kuid Euroopa keelte kotinimetused, taskunimetuste eelkäijad, on enamasti etümoloogiliselt läbipaistmatud. Nii rajaneb ka sõna kaugas laenualuseks pakutud lt kabata, ka kabats 'tasku' etümoloogia oletusel, et see võib vahest olla seotud verbidega ld kabéti ( $k a \tilde{b a} \sim k a \tilde{b i}$, kabéjo) 'rippuma', it kabināt 'kinnitama, ühendama, haakima' (ME II: 129). Seda Jānis Endzelīnsi pakutud etümoloogiat kordab Konstantīns Karulis ja oletab tähendusarengut 'külgeriputatu(d) / külgekinnitatu(d)' $\rightarrow$ 'külge riputatud / haakidega külge kinnitatud kott' $\rightarrow$ 'rõivasse töödeldud tasku' (LEV I: 365-366). Kuigi kotinimetuste ja kalapüügiriistade või nende osade nimetused võivad olla ühistüvelised, pole selge, kas läti kab-tüvelised kalapüügivahendi nimetused kabe, kabis, kabene, kabris, kablis jt 'kuurits' kuuluvad samasse sõnapessa kui taskut tähistav kabata. 
Leedu sõna kabãte 'vitstest punutud kalapüügiriist / prietaisas žuvims gaudyti, krytė, graibštas' (http:wwww.lkz.lt) peetakse slaavi päritolu sõnaks - vrd ukr хо́бот, ? vn murd хабо́ша хобо́ша 'mõrd, rüsa' (Dahl IV: 540, 555), mis on oletatavasti suguluses juba eespool nimetatud ld verbiga kabéti 'rippuma' (vt Vasmer IV: 252; Černyh II: 345-346). Selles kontekstis võib veel tähelepanu juhtida eesti unarsõnale kabar : kabara 'seljapaun, ranits', mida tänapäeva eesti sõnaraamatud ei kajasta ja mille võimaliku murdetausta kohta puuduvad andmed. Kabar leidub „Eesti õigekeelsuse-sõnaraamatus“ (EÕS II: 155) ja sellistes kakskeelseis sõnaraamatuis nagu Arumaa jt 1940-1947 (ранец 'ranits, seljapaun, kabar') ja Tuksam 1934-1939 (Tornister 'ranits, [selja-]paun, kabar; seljakott'). Kabar (ka jahikabar) esineb korduvalt Ernst Särgava romaanis „Lähme linna kirjutama, oma elu kergendama“ tähenduses 'seljakott, jahipaun', nt „Körber võttis sadula küljest kabara, viskas selga, tõusis sadulasse .." (I: 193). Võimalik, et kabar on loodud vn кобýpá 'nahkvutlar revolvri või püstoli kandmiseks (õla- või vöörihmal)' eeskujul. See sõna on turgi päritolu (nt türgi kubur 'silindrikujuline pikk nõu, igasugune torukujuline ese jt'), teateid кобýpá jt esinemise kohta vene keeles on alates XIX sajandi I poolest (Vasmer II: 269; Černyh I: 407).

Kaugas on väga suure tõenäosusega vanem balti laen, lähtunud *kauktüvest, mille võimalik i-e arhetüüp on kas * $(s) k e u$ - *kou- 'kumeraks tegema, kumer, õõnestis, õõs' (LEW I: 231 sub káušas; vt ka IEW II: 589 *keu-k) ja/või *(s)keu- '(kinni) katma, (sisse) mähkima' (vt IEW II: 951). Selle arvuka ja mitmekesise semantikaga balti sõnapesa liikmed on nt ld káuke 'mask, näokate, gaasimask / Maske', káukè '1. väike uhmer peki peeneks tampimiseks, puust kopsik, liud, vaagen / piestelè lašiniams grūsti, taukė; 2. puust kopsik või kauss (paadist vee või jääaugust jää ammutamiseks) / toks medinis kaušas ar dubenèlis (vandeniui iš laivelio ar ledams iš aketès semti)', kaukẽlè dem 'puukauss / hölzerne Schüssel', kaũkas kaũkis kaũkè káukè 'puuking / klumpè', káukolè káukolis, káukolas 'kolp, (surnu) pealuu / (Hirn)schädel', kãukaras 'laup; kukal / kakta; pakaušis', kiáuklas kiáukutas 'kate, kest / Hülle, Schale, Hülse, Gehäuse', kaukõre' '1. puunõu peki tampimiseks, uhmer; puust nõu rasva ja peeneks tambitud peki hoidmiseks / medinis indas lašiniams grūsti, grūstuvė, piesta; 2. puunõu rasva ja peeneks tambitud peki hoidmiseks / medinis indas taukams ar sugrūstiems lašiniams laikyti', kiauklẽ jt 'koda, karp, teokarp / Gehäuse, Schneckenhaus, Muschelschale' jt, lt ? kàukala² 'kuljus, kelluke 
/ die Schelle', kaukuris: kaukuŗa ķipis 'nõu leili viskamiseks / garmetis' (LEW I: 231-232; http://www.lkz.lt; ME I: 174). Sissetöödeldud rõivatasku on nii uus nähtus, et seda semantikat ei saanud balti laenualus kuidagi kanda. Samuti tuleb meeles pidada, et M kaugas ei tähista veel rõivataskut tänapäevases tähenduses, mida on võimalik selgendada Hallistest kirja pandud kirjeldusega: Kaugas õmmelti mes'te 'ammel 'sisse. 'Sõlgug olli iist 'kinni. Mes'te 'ammel ómmelti sissepoole piha_bäle ja rinna ette viil tõine kõrd rõ̃̃vast. Pää_augu mant jäeti katespoole augu 'valla, ninda_t käsi ‘sisse 'mahtus. Siss sai kaukas midäg panna, ’piipu ja tubakukotti ve --- (VKM VII: 134-135). On usutavaid etümoloogiaid, mis kõnelevad sellest, et rõivanimetus on võinud olla taskunimetuse lähtekohaks, nt sm p(r)akkari (p)lakkari 'tasku' < rts murd brackor 'püksid' (SSA 2: 41). Sõna kaugas võimalikke laenualuseid võiks nt olla leedu särginimetuse kaukaĩ pl eelkäija, kuid selle leedu sõna etümoloogia pole selge. Vanimaid tasku eelkäijaid oli nahatükk, mis servahormadesse aetud naharibaga tõmmati ümmarguseks kotikeseks, pungaks, pusaraks. Seesugune nahast vööpung kuulus 5300 aastat tagasi elanud jäämehe Ötzi varustusse ja oli mõeldud tuletegemisvahendite ja luunaaskli hoidmiseks. Sama tüüpi praktilisi pusaraid pisemate tarbeesemete kaasaskandmiseks on edukalt kasutatud aastatuhandeid. Eelöeldut silmas pidades sobivad laenualuse semantilisse välja *kauk-tüve tuletised káukẻ 'mask, näokate' ja kiáuklas kiáukutas 'koor, kate, kest', samuti *kauš-tüvest lähtunud kiaũšis 'muna, munand'. Ülemal loetletud taskunimetused tasku, vikk, kalits, kulit jt on eesti keelde laenatud eri keelte taskut tähistavatest laenualustest. Kaugas nende hulka ei kuulu, sest pärineb märksa vanemast laenukihistisest. Taas tuleb tõdeda, et levila ei ole keelendi vanuse üle otsustamisel määrav. Balti laen *kauka on muganenud as-lõpuliste nimisõnadega kujul kaugas, vrd lauk > Hls laugas 'murulauk', louk > lõugas 'kolle', rõuk > Saa Hls rõugas 'vankri osa' jt.

Balti laenualusest *kaukāl- *kaukōl- 'ummik, puutüvest õõnestatud nõu', mille jätkaja on nt ld kaukẽle 'puukauss' on laenatud lms *kaukal-: lvS kougil, K koùgõl (< kaugal-) 'leivaküna / Brottrog, Backtrog', vdj kaukalo kaukolo '(puust õõnestatud sea-, pesu-) küna', sm kaukalo 'küna, mold', (Kalevala) 'pitkänomainen, matala ruokaastia; sikojen syöttöastia' (Jussila 2009: 110), is kaukola kaugolo 'puinen allas', vps kaukol, kaukal, koukol 'pellavannuppu', võib-olla ka mo kovâl 'küna'. Balti laen on ilmselt ka eL (Räp) -kauk: kilikauk 'teokarp', krj kaukelo 'simpukan 
kuori' laenualusest, mille jätkaja on nt ld kiauklẽ jt 'koda, karp, teokarp. Soome sõnu kaukalo 'der Trog' ja karin-k[aukalo] 'die Schnecke, die Muschel' on leedu sõnadega kaûkólas = kaûkỏlè, kaûke 'persona lignea', kaukélè 'medínys bljúdas' kõrvutanud 1879.-1890. ja 1902.-1903. a paiku Kazimieras Jaunius (vt Jaunius 1972: 249, 262). Ilmne balti laen on ka lvK kogīl 'peakolu, pealuu' (Viitso, Ernštreits 2012: 131), mis lähtub laenualusest, mille jätkaja on nt ld káukolis jt 'kolp, (surnu) pealuu', kuigi on ootuspäratult muganenud keelde lühikese $o$-ga. Lms vastete - $V l$-järjend annab edasi laenualuse produktiivset deverbaaliliidet $* \bar{a} l-\sim * \bar{o} l-$, mille olulisi tähendusi on tegevuse tulemuse edasiandmine (Ambrazas 1993: 98 jj; balti l-liidete kohta vt ka Endzelīns 1951: 340 jj).

Y. H. Toivonen on omal ajal avaldanud arvamust, et kaukalo võib olla tuletis kauka-tüvest 'kauge, kaua', põhjendades seda seigaga, et kaukalo on piklik nõu (Toivonen: 1945: 403). Selle ebaveenva, pigem rahvaetümoloogiana tunduva seletuse esitavad ka SKES (I: 173) ja SSA (1:331). Balti laenualuses on tallel viide ummiknõude valmistustehnikale.

*kauk-tüve kõrval on balti keeltes ka muid tüvevariante, sh sibilandiga *kauš-: nt ld káušas 'kopsik, jooginõu; teokarp; kahv (võrkkott kalade püüdmiseks); kolp jt', kaũšti (kaũšia, kaũšè) 'õõnestama, uuristama jt', kaušakỹs 'suurem' kopsik, kopp', káušenos pl 'puukingad', kaušùkas 'teokarp, jõekarp jt', kiáušas kiáuše 'kolju, pealuu', kiaũšis 'muna, munand', It kaûss 'pealuu; jooginõu; kauss; kulp, lusikas jt', ? kुaukste 'pealuu' (LEW I: 231-232; IEW II: 953 sub (s)keu- $k$ '-; ME II: 357; Otkupščikov 1967: 168). *kauša-tüvega on seotud lms *kauha: L kahv 'puulusikas' jt (vt eespool).

Artikkel on valminud autori vabal tahtel ega ole seotud ühegi rahastatava projektiga.

\section{Lühendid $^{1}$}

blt - balti keeled; lvK - kuraliivi keel; lvS - salatsiliivi keel; pl - pluural; sgp singulari partitiiv

Esitatud on üksnes need lühendid, mida aastaraamatu lühendinimestikus pole. 


\section{Kirjandus}

Ambrazas, Saulius 1993. Daiktavardžių darybos raida. Lietuvių kalbos veiksmažodiniai vediniai. Vilnius: Mokslo ir enciklopedijų leidykla.

Arumaa jt 1940-1947 = Vene-eesti sõnaraamat. Koost. Peeter Arumaa, Boriss Pravdin, Johannes Voldemar Veski. Tartu: Teaduslik Kirjastus.

Blokland, Rogier 2009. The Russian Loanwords in Literary Estonian. (= Veröffentlichungen der Societas Uralo-Altaica 78.) Wiesbaden: Harrassowitz Verlag.

Būga, Kazimieras 1959. Rinktiniai raštai. II. Vilnius: Valstybinè politinės ir mokslinès literatūros leidykla.

Černyh 1999 = Павел Черных. Историко-этимологический словарь современного русского языка. I-II. Москва: Русский язык.

Dahl = Владимір Даль 1880-1882. Толковый словарь живаго великорускаго языка Владиміра Даля I-IV. С.-Петербургъ-Москва: Издание книгопродавца-типографа М. О. Вольфа.

EEW = Julius Mägiste 1982-1983. Estnisches etymologisches Wörterbuch. I-XII. Helsinki: Finnisch-Ugrische Gesellschaft.

EH = Jānis Endzelīns, Edīte Hauzenberga 1934-1946. Papildinājumi un labojumi K. Mülenbacha Latviešu valodas vārdnīcai. I-II. Rīgā: Grāmatu apgāds.

EKMS = Andrus Saareste 1958-1963. Eesti keele mõisteline sõnaraamat. I-IV. Dictionnaire analogique de la langue estonienne. Avec un index pourvu des traductions en français. (= Eesti Teadusliku Seltsi Rootsis väljaanne nr. 3.) Stockholm: Vaba Eesti.

EMS = Eesti murrete sõnaraamat. I- , 1994- . Tallinn: Eesti Keele Instituut.

Endzelīns, Jānis 1951. Latviešu valodas gramatika. Rīgā: Latvijas valsts izdevniecība.

ERL IV = Eesti rahvalaulud. Antoloogia. IV, 1974. Toim. Ülo Tedre. Eesti NSV Teaduste Akadeemia Keele ja Kirjanduse Instituut. Tallinn: Eesti Raamat.

ÈSSJa 11 = Этимологический словарь славянских языков. Праславянский лексический фонд. 11, *konьсь-*kotьna(ja), 1984. АН СССР, Институт русского языка. Отв. ред. О. Н. Трубачев. Москва: Наука.

EÕS = Eesti õigekeelsuse-sõnaraamat. I-III, 1925-1937. „Eesti keele õigekirjutusesõnaraamatu" II täiendatud ja parandatud trükk. Tartus: Eesti Kirjanduse Seltsi kirjastus.

Hupel, August Wilhelm 1780. Ehstnische Sprachlehre für beide Hauptdialekte den revalschen und den dörptschen; nebst einem vollständigen Wörterbuch. Hrsg. August Wilhelm Hupel. Riga- Leipzig: bey Johann Friedrich Hartknoch.

IEW = Julius Pokorny. Indogermanisches etymologisches Wörterbuch. I-II, 1949-1959. Bern: A. Francke AG Verlag,. 
Jaunius, Kazimieras 1972. Kalbininko Kazimiero Jauniaus rankraštinis palikimas. Katalogas ir publikacijos. Рукописное наследие языковеда Казимераса Яунюса. Каталог и публикации. Parengė S. Skrodenis. Spec. redaktorius A. Lukošiūnas. Vilnius: Lietuvos TSR valstybinė respublikinè biblioteka.

Jussila, Raimo 2009. Kalevalan sanakirja. Helsinki: Otava.

Kettunen, Lauri 1938. Livisches Wörterbuch mit grammatischer Einleitung. (= Lexica Societatis Fenno-Ugricae V.) Helsinki: Suomalais-Ugrilainen Seura.

Konsin, Kalju 1977. Vöötaskud. Tallinn: Eesti NSV Haridusministeerium.

LEV I = Konstantīns Karulis 1992. Latviešu etimoloǵijas vārdnīca. I, A-O. Rīga: Avots.

LEW = Ernst Fraenkel 1962-1965. Litauisches etymologisches Wörterbuch. I-II. Heidelberg: Carl Winter, Universitätsverlag, Göttingen: Vandenhoeck \& Ruprecht.

ME = K. Mülenbacha Latviešu valodas vārdnOica. I-IV, 1923-1932. Redig̣ejiis, papildinājis, turpinājis Jānis Endzelīns. Rīgā: Izdevusi Izglītîbas ministrija.

Mikkola, Jooseppi Julius 1938. Die älteren Berührungen zwischen Ostseefinnisch und Russisch. (= SUST LXXV.) Helsinki: Suomalais-Ugrilainen Seura.

Otkupščikov 1967 = Юрий Откупщиков. Из истории индоевропейского словообразования. Ленинград: Издательство Ленинградского университета.

Posti, Lauri 1942. Grundzüge der livischen Lautgeschichte. (= SUST LXXXV.) Helsinki: Suomalais-Ugrilainen Seura.

Raun, Alo 1982. Eesti keele etümoloogiline teatmik. Rooma-Toronto: Maarjamaa.

Saareste, Albert 1924. Leksikaalseist vahekordadest eesti murretes I. Analüüs 60 kaardi ja 1 skeemiga. Résumé: Du sectionnement lexicologique dans les patois estoniens. I. Analyse avec 60 cartes et 1 esquisse schématique (= Acta et Commentationes Universitatis Dorpatensis. B VI, 1.) Tartu: Kirjastus-Ühisus „Postimehe“ trükk.

Smoczyński, Wojciech 2000. Litewskie wyrazy typu \{indas\}, \{apstas\} oraz typu \{sam̃das\}. - Балто-славянские исследования 1998-1999. XIV. Сборник научных трудов. Отв. ред. Т.-М. Судник. Москва: Наука, 155-174.

SSA = Suomen sanojen alkuperä. Etymologinen sanakirja. 1-3, 1992-2000. Päätoim. Erkki Itkonen, Ulla-Maija Kulonen. (= Suomalaisen Kirjallisuuden Seuran toimituksia 556, Kotimaisten kielten tutkimuskeskuksen julkaisuja 62.) Helsinki: Suomalaisen Kirjallisuuden Seura, Kotimaisten kielten tutkimuskeskus.

Särgava, Ernst 1968. Lähme linna kirjutama, oma elu kergendama. I-II. Tallinn: Eesti Raamat.

Toivonen, Y. H. 1945. Etymologisia huomioita. - Virittäjä 3, 401-409. 
Troska jt 1995 = Gea Troska, Ants Viires, Ellen Karu, Lauri Vahtre, Igor Tõnurist. Eesti rahvakultuuri leksikon. Koost. ja toim. Ants Viires. Tallinn: Eesti Entsüklopeediakirjastus.

Tuksam 1934-1939 = Saksa-eesti sõnaraamat. Deutsch-estnisches Wörterbuch. Koost. Georg Tuksam. Käsikirja läbi töötanud ja redigeerinud Elmar Muuk. Tartu: Kool.

Uibo, Udo 2010. Etümoloogilisi märkmeid X. kaugas. - Keel ja Kirjandus 10, $758-759$.

Vaba, Lembit 2009. Rend ja laud. Kisklauast söögilauaks. - Keel ja Kirjandus 10, 779-784.

Vaba, Lembit 2012. Kura kaja liivi keeles. - Pühendusteos emeriitprofessor Mati Hindi 75. sünnipäevaks. Koost. ja toim. Reili Argus, Annika Hussar ja Tiina Rüütmaa. (= Tallinna Ülikooli eesti keele ja kultuuri instituudi toimetised 14.) Tallinn, 177-202.

Vasmer $=$ Макс Фасмер 2004. Этимологический словарь русского языка. I-IV. Перевод с немецкого и дополнения академика РАН О. Н. Трубачева. Москва: Астрель Аст.

Vestring, Salomo Heinrich 1998. Lexicon Esthonico Germanicum. Eesti-saksa sõnaraamat. Tartu: Eesti Kirjandusmuuseum.

Viitso, Tiit-Rein, Valts Ernštreits 2012. Līvõkīel-ēstikīel-leţkīel sõnārōntõz. Liivieesti-läti sõnaraamat. Lībiešu-igauņu-latviešu vārdnīca. Tartu-Rīga: Tartu Ülikool, Latviešu valodas aǵentūra.

VKM VII = Ennemuistitsel Mulgimaal. 2008. Toim. Helju Kaal, Mari Must, Eevi Ross. (= Valimik korrespondentide murdetekste VII.) Tallinn: Emakeele Selts.

VMS II = Väike murdesõnastik. II, 1989. Toim. Valdek Pall. Koost. Anu Haak, Evi Juhkam, Marja Kallasmaa, Ann Kask, Ellen Niit, Piret Norvik, Vilja Oja, Aldi Sepp, Jaak Simm, Jüri Viikberg. Eesti NSV Teaduste Akadeemia Keele ja Kirjanduse Instituut. Tallinn: Valgus 1989.

Wiedemann, Ferdinand Johann 1973 (1893). Eesti-saksa sõnaraamat. Estnischdeutsches Wörterbuch. Neljas, muutmata trükk teisest, Jakob Hurda redigeeritud väljaandest. Vierter unveränderter Druck nach der von J. Hurt redigierten Auflage. Tallinn: Valgus.

\section{Võrgumaterjalid}

Eesti regilaulude andmebaas. http://www.folklore.ee/regilaul/andmebaas.

Lietuvių kalbos žodyno (t. I-XX, 1941-2002) elektroninio varianto I leidimas 2005. http://www.lkz.lt. 


\section{The alternative etymologies}

\section{LEMBIT VABA}

The article presents alternative etymologies for the Estonian words koost '(wooden) spoon' and kaugas 'men's shirt breast with a double waist, used as a pocket; wallet' and the Northern Finnic word represented by Finnish kaukalo 'trough'. The word koost is found primarily on the western Estonian islands. Julius Mägiste has proposed a Russian etymology for it, as a borrowing based on *kopusta 'mixing tool'. Mägiste's Russian etymology presumes the phonological development chain *kopusta $>$ *koßusta $>$ *kovosta $>$ koost, proposed specifically for this case, which is implausible. koost is most likely of Baltic origin, from a loan base the successors of which are Lithuanian kaũstè / kaustẽ 'vessel hollowed out from a tree trunk, drinking horn', Latvian kaũšşins 'ladle' etc. Upon its borrowing, the Baltic $a u$ was replaced by ou, which later developed into a long $\bar{o}$. This kind of substitution and phonological development is characteristic of Livonian, where vowels are in quantitative and mostly also qualitative paradigmatic alternation, including ou : $\bar{o}$. The borrowing has presumably come to Estonian via Livonian, where it is no (longer) recorded. Although the presumed Baltic loan base lacks phonological features of diagnostic value, the word's geographical distribution indicates that it could have been borrowed from Curonian.

The proposed connection between kaugas 'men's shirt breast with a double waist, used as a pocket; wallet' and Latvian kabata 'pocket' requires a remarkably complicated phonological adaptation for a relatively recent borrowing and is unconvincing. kaugas is most likely an older Baltic loan, having originated from the stem *kauk-, the possible Indo-European archetype of which is * (s)keu- / *kou'to make curved, curved, hollow, cavity' and/or *(s)keu- 'to cover (up), wrap (up)'. The members of this large and diverse Baltic word family include Lithuanian káuke 'mask, face cover, gas mask', kiáuklas / kiáukutas 'cover, shell', káuke 'mortar, wooden ladle, dish, basin etc.', kaukẽle 'wooden dish' and others. kaugas does not denote a pocket on a garment in today's meaning. A pocket woven/sewn into a piece of clothing is a sufficiently new phenomenon that the Baltic loan base could not possibly have carried that meaning. Among the oldest forerunners of pockets was a piece of skin, which could be pulled with the aid of a sheep-split into the shape of a small round bag or purse. In this context, derivations of the *kauk- stem such as káuke and kiáuklas / kiáukutas can be seen to fit in the semantic field of the loan base. Estonian words for 'pocket' such as tasku, vikk, 
kalits, kulit etc. have been borrowed into Estonian on the basis of words in other languages denoting pockets. kaugas is not among them, as it belongs to a much earlier loanword stratum.

The Baltic loan base *kaukāl- / *kaukōl- 'vessel hollowed out from a tree trunk', the successor of which is e.g. Lithuanian kaukẽle 'wooden dish' has been borrowed into Finnic as *kaukal-: Salaca Livonian kougil, Karelian koùgõl 'kneading trough', Votic kaukalo / kaukolo 'trough hollowed out of wood', Finnish kaukalo 'trough' etc. The sequence $-V l$ in these Finnic words is the representation of the loan base's productive deverbal affix $* \bar{a} l-/ * \bar{o} l-$, one of the essential meanings of which is conveying the result of an action. An earlier explanation held kaukalo and its equivalents to be derived from the stem kauka- 'distant, far, for a long time', on the basis of the fact that kaukalo denotes an oblong vessel. This is, however, merely a folk etymology. The Baltic loan base contains a reference to the way in which such vessels were made.

Keywords: etymology, loanwords, Estonian, Finnic languages, Baltic languages

Lembit Vaba

phorest45@gmail.com 